\title{
Rechazo agudo en implante renal por ecografia
}

\author{
E. Cao Avellaneda*, M.Y. López Martín**, R.E. Granados Galindo***, M.E. Rincón Vergara***, \\ P. Escovar Díaz***
}

\begin{abstract}
${ }^{*}$ Hospital Universitario Virgen de la Arrixaca. Murcia. ${ }^{* *}$ Servicio de Imagenología. Valencia. ***Instituto Docente de Urología. Venezuela.
\end{abstract}

Actas Urol Esp 2006; 30 (1): 100

$\mathrm{H}$ ombre de 59 años que acude de manera urgente por oligoanuria y malestar general. Trasplantado renal hace 5 meses en tratamiento con triple terapia sin episodios previos de rechazo. Creatinina elevada respecto a último control. En la ecografia se detecta aumento del índice de resistencia vascular en un riñón discretamente aumentado de tamaño. Destaca el importante engrosamiento de la pared de pelvis y de la totalidad de uréter, en la imagen a nivel distal (Figs. 1 y 2), hallazgo infrecuente y motivo principal para esta comunicación. Es tratado de manera experimental con bolos de corticoides, consiguiendo una buena respuesta inicial. La función renal y el control ecográfico fueron normales a las 2 semanas del inicio del tratamiento.

El rechazo agudo acontece principalmente dentro de los 6 primeros meses. La ecografia como prueba diagnóstica aporta como signo

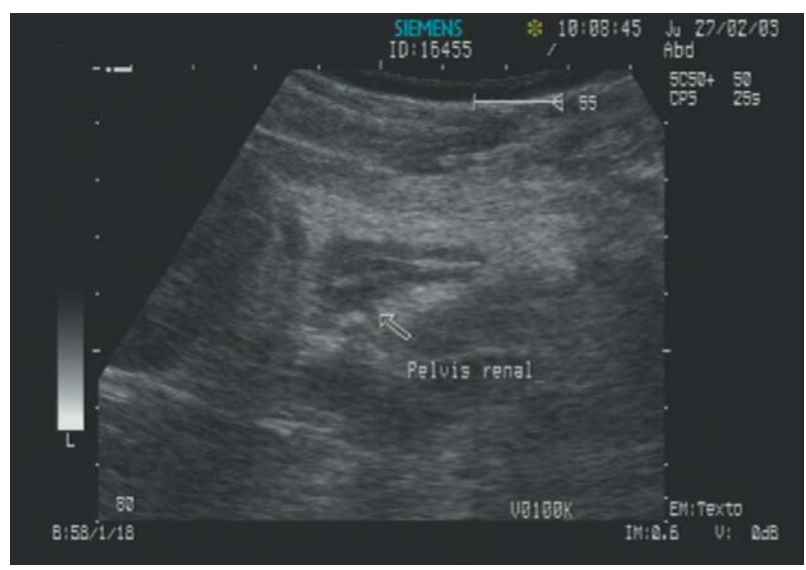

FIGURA 1

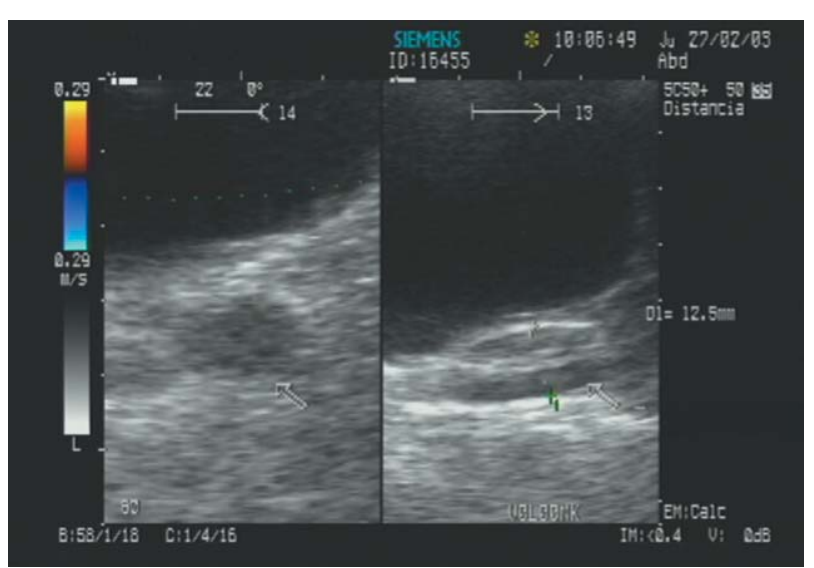

FIGURA 1

principal el aumento del índice de resistencia (más de 0,70 m/s), mediante el estudio doppler de su vascularización. Otros posibles signos asociados son el aumento del volumen renal con modificación de su morfología, fundamentalmente en los diámetros transversales, el aumento y menor ecogenicidad del seno renal, y un engrosamiento de la pared de pelvis y uréter, hallado de manera pronunciada en este caso. El principal problema en el diagnóstico por ecografia es ser una técnica observador dependiente, hecho que produce un amplio rango en la sensibilidad y la especificidad.

Dr. E. Cao Avellaneda

E-mail: enriquecao@hotmail.com

(Trabajo recibido el 17 de mayo 2005) 